\title{
ANALISIS KEBUTUHAN AIR IRIGASI SAWAH PADI PADA DAERAH IRIGASI CIUJUNG KECAMATAN CIRUAS
}

\author{
Ammar Hariz ${ }^{1}$, Rino Dwi Sadi², Fitri Aida Sari ${ }^{3}$ \\ 1, 2, ${ }^{3}$ Program Studi Teknik Sipil, Universitas Banten Jaya, Jl. Raya Ciwaru II No. 73 Kota Serang Banten \\ Email: arislover04@gmail.com \\ Email: rsadisons@gmail.com \\ Email: fitriaidasari@unbaja.ac.id
}

\begin{abstract}
ABSTRAK
Air merupakan kebutuhan pokok seluruh makhluk hidup baik manusia, hewan dan tumbuhan. Kebutuhan air bagi manusia meliputi aspek seperti rumah tangga, pertanian, industri dan lainlain. Namun untuk ketersediaan air pada setiap tempat berbeda-beda, maka diperlukan suatu pengelolaan pada sumber air agar dapat mengisi kekurangan air untuk daerah yang keterbatasan air terutama pada aspek pertanian. Penelitian ini dilakukan di saluran sekunder kesampangan dan bayongbong daerah irigasi Ciujung Kecamatan Ciruas. Permasalahan kebutuhaan air akan timbul jika terjadi kekurangan air di petak-petak sawah hingga terjadinya perebutan air akibat penggunaan konsumtif. Maka diperlukan data kebutuhan air tiap-tiap saluran untuk dijadikan acuan agar air yang diperlukan tidak berlebihan dan tidak kekurangan serta jadwal penanaman yang sesuai dengan jadwal tanam. Penulis melakukan pengumpulan data saluran, data klimatologi, koefisien tanaman, lalu menentukan penggunaan konsumtif, lalu menentukan kebutuhan air saat penyiapan lahan dan tiap-tiap fase pertumbuhan. Tujuan penelitian ini untuk mengetahui kebutuhan air untuk saluran sekunder kesampangan dan bayongbong, untuk mengetahui cara pembagian pengaliran lahan sawah di saluran sekunder kesampangan dan bayongbong dan untuk mengetahui jadwal tanam yang seharusnya dilaksanakan pada saluran sekunder kesampangan dan bayongbong. Hasil penelitian ini menunjukkan bahwa kebutuhan air saat pengolahan lahan sebesar 0,79 liter/detik, anakan 0,47 liter/detik, anakan maksimum 0,77 liter/detik, berbunga 0,72 liter/detik dan pematangan 0,33 liter/detik. Jika terjadi penutupan air dari bendung maka dilakukan sistem rotasi/bergiliran dalam menggunakan air dan melakukan tanam sesuai dengan jadwal penanaman yang sudah ditentukan.
\end{abstract}

Kata kunci: Kebutuhan Air Sawah, Pembagian Air, Jadwal Tanam 


\section{PENDAHULUAN}

Dalam penelitian ini penulis melakukan kajian pada Daerah Irigasi Ciujung Kecamatan Ciruas Kabupaten Serang tepatnya di saluran sekunder kesampangan dan saluran sekunder bayongbong. Luas lahan yang harus teraliri air pada saluran sekunder kesampangan seluas 588,2 ha dengan panjang saluran $\pm 6,04 \mathrm{~km}$ dan saluran sekunder bayongbong sepanjang $\pm 1,47 \mathrm{~km}$ dengan luas area 350,1 ha. Pada beberapa tahun terakhir instansi terkait dalam pengelolaan jaringan irigasi Ciujung yaitu Dinas Pekerjaan Umum dan Penataan Ruang Kabupaten Serang Bidang Sumber Daya Air UPTD PUPR Kecamatan Ciruas, menerima banyak pengaduan mengenai kekurangan air terutama pada saluran irigasi kesampangan dan saluran irigasi bayongbong serta beberapa masalah lainnya seperti rata-rata penggunaan air untuk lahan sawah dianggap konsumtif, di saluran ini juga terdapat beberapa petani yang penggunaan airnya tidak sesuai dengan jadwal pembukaan air, terjadinya perebutan kebutuhan air untuk lahannya masing-masing, hingga tidak serentaknya jadwal penanaman dan panen. Maka diperlukannya perhitungan ulang kebutuhan air irigasi sawah padi agar terpenuhinya kebutuhan air tersebut. Hasil penelitian ini diharapkan dapat memberikan kontribusi dalam menambah pengetahuan tentang kebutuhan air irigasi sawah sehingga dapat menjadi pertimbangan bagi petani dan mantri untuk mengelola kebutuhan air di sawah layanan saluran sekunder kesampangan dan saluran sekunder bayongbong serta bagi pembaca diharapkan dapat digunakan sebagai salah satu referensi penelitian dalam mencari kebutuhan air di sawah, salah satunya di saluran sekunder kesampangan dan saluran sekunder bayongbong.

\section{METODOLOGI PENELITIAN}

Langkah-langkah penelitian ini adalah sebagai berikut :

1. Pengumpulan data saluran dan luas area garapan

Tabel 1 Data Area Saluran

\begin{tabular}{rlcc}
\hline No & Nama Saluran & Areal Lahan (Ha) & Luas Areal Garapan (Ha) \\
\hline $\mathbf{1}$ & Saluran Sekunder & $\mathbf{5 8 8 , 2}$ & \\
& Kesampangan & 103,7 & 56 \\
a & KS.3.ki & 67,5 & 32 \\
b & KS.3.ka & 125 & 60 \\
c & KS.2 & 121,2 & 60 \\
d & KS.1.ki & 126,4 & 60 \\
e & KS.ka.1 & 44,4 & 20 \\
f & KS.ka.2 & $\mathbf{3 5 0 , 1}$ & \\
$\mathbf{2}$ & Saluran Sekunder & 130,3 & 60 \\
a & Bayongbong & 104,3 & 60 \\
b & BYB.2.ki.1 & 115,5 & 60 \\
c & BYB.1.ki & & \\
\hline
\end{tabular}

Sumber : UPTD PUPR Kec. Ciruas

2. Menentukan besarnya nilai evapotranspirasi (ETo) daerah setempat dengan menggunakan aplikasi Cropwat versi 8 beta. 


$\begin{array}{lccccccc}\text { Month } & \begin{array}{c}\text { Min Temp } \\ { }^{\circ} \mathrm{C}\end{array} & \begin{array}{c}\text { Max Temp } \\ { }^{\circ} \mathrm{C}\end{array} & \begin{array}{c}\text { Humidity } \\ \text { o }\end{array} & \begin{array}{c}\text { Wind } \\ \mathrm{km} / \text { day }\end{array} & \begin{array}{c}\text { Sun } \\ \text { hours }\end{array} & \begin{array}{c}\text { Rad } \\ \mathrm{MJ} / \mathrm{m}^{2} / \text { day }\end{array} & \begin{array}{c}\text { ETo } \\ \text { mm/day }\end{array} \\ \text { January } & 25.0 & 29.0 & 83 & 94 & 4.5 & 16.6 & 3.61 \\ \text { February } & 26.4 & 28.6 & 83 & 79 & 5.8 & 18.9 & 4.02 \\ \text { March } & 24.7 & 28.4 & 83 & 80 & 4.1 & 15.9 & 3.41 \\ \text { April } & 26.5 & 29.1 & 83 & 77 & 5.6 & 17.2 & 3.65 \\ \text { May } & 26.8 & 29.4 & 79 & 78 & 6.2 & 16.8 & 3.60 \\ \text { June } & 25.9 & 28.8 & 78 & 66 & 5.6 & 15.2 & 3.21 \\ \text { July } & 26.0 & 28.4 & 75 & 89 & 7.3 & 17.8 & 3.72 \\ \text { August } & 25.8 & 28.3 & 74 & 89 & 7.2 & 18.9 & 3.98 \\ \text { September } & 25.9 & 28.8 & 72 & 89 & 7.8 & 21.2 & 4.45 \\ \text { October } & 27.5 & 30.4 & 71 & 83 & 7.2 & 20.9 & 4.63 \\ \text { November } & 25.2 & 30.6 & 72 & 80 & 7.0 & 20.4 & 4.49 \\ \text { December } & 25.7 & 29.6 & 81 & 78 & 3.9 & 15.5 & 3.49 \\ \text { Average } & 25.9 & 29.1 & 78 & 82 & 6.0 & 17.9 & 3.86\end{array}$

Gambar 1 Hasil Perhitungan ETo (sumber : BMKG Serang)

3. Menentukan koefisien tanaman $(\mathrm{Kc})$

4. Menentukan penggunaan konsumtif tanaman (ETc)

5. Dihitung kebutuhan air untuk persiapan lahan sawah dengan menggunakan rumus persamaan Van de Goor dan Zijlstra dalam buku kriteria perencanaan irigasi kp.01, tahun 2013.

6. Menentukan nilai perkolasi.

Tabel 2 Data Perkolasi

\begin{tabular}{cc}
\hline Jenis Tanah & Perkolasi (mm/hari) \\
\hline Tekstur Berat & 1 \\
Tekstur Sedang & 2 \\
Tekstur Ringan & 5 \\
\hline
\end{tabular}

Sumber : Irigasi dan Bangunan Air, 1997

Diambil data perkolasi sebesar $2 \mathrm{~mm} /$ hari karena jenis tanah bertekstur sedang.

7. Menentukan nilai evaporasi.

8. Penggantian lapisan air dilakukan 2 kali masing-masing $50 \mathrm{~mm}$ selama sebulan.

9. Menentukan hujan efektif.

\begin{tabular}{lr} 
& \multicolumn{1}{c}{$\begin{array}{c}\text { Rain } \\
\text { mm }\end{array}$} \\
January & 273.0 \\
February & 223.6 \\
March & 121.5 \\
April & 105.3 \\
May & 105.9 \\
June & 90.1 \\
July & 89.7 \\
August & 39.8 \\
September & 56.3 \\
October & 87.2 \\
November & 138.9 \\
December & 170.8 \\
& \\
Total & 1502.1
\end{tabular}

Gambar 2 Hujan Bulanan (sumber : BMKG Serang) 
10. Menentukan kebutuhan air irigasi sawah (NFR)

11. Mengkonversi satuan kebutuhan air irigasi dari $\mathrm{mm} / \mathrm{hari}$ ke liter/detik.

12. Cara pembagian air irigasi.

13. Jadwal tanam yang seharusnya dilakukan.

\section{DATA DAN ANALISA}

\subsection{Data fase pertumbuhan padi}

Padi biasanya tumbuh \pm 120 hari tergantung pada jenis tanaman padi, permukaan tanah dan iklim yang terdapat di daerah tersebut. Pertumbuhan padi dapat dibedakan dalam tiap fase antara lain masa vegetatif dan masa generatif (Nugroho, 2017). Masa vegetatif dimulai sejak masa tanam sampai dengan masa anakan maksimu sedangkan masa generatif dimulai sejak masa anakan maksimum sampai butir padi matang dan siap panen. Berikut tabel masa pertumbuhan padi :

\begin{tabular}{cccc}
\multicolumn{4}{c}{ Tabel 3 Fase Pertumbuhan Padi } \\
\cline { 2 - 4 } No & Fase & Jumlah Hari \\
\hline 1 & & Pengolahan lahan & 30 \\
2 & \multirow{2}{*}{ Vegetatif } & Tanam & 0 \\
3 & Anakan & 20 \\
4 & & Anakan Maksimum & 34 \\
5 & \multirow{2}{*}{ Generatif } & Berbunga & 35 \\
6 & & Pematangan & 31 \\
\hline
\end{tabular}

(sumber : Mantri UPTD PUPR Kec. Ciruas)

3.2. Data evapotranspirasi (ETo)

Data evapotranspirasi didapat dari BMKG Serang, lalu dihitung menggunakan aplikasi Cropwat versi 8 beta buatan $F A O$. Berikut hasil data tersebut:

$\begin{array}{lccccccc}\text { Month } & \begin{array}{c}\text { Min Temp } \\ { }^{\circ} \mathrm{C}\end{array} & \begin{array}{c}\text { Max Temp } \\ { }^{\circ} \mathrm{C}\end{array} & \begin{array}{c}\text { Humidity } \\ \circ\end{array} & \begin{array}{c}\text { Wind } \\ \mathrm{km} / \text { day }\end{array} & \begin{array}{c}\text { Sun } \\ \text { hours }\end{array} & \begin{array}{c}\text { Rad } \\ \text { MJ/m } / \text { day }\end{array} & \begin{array}{c}\text { ETo } \\ \text { mm/day }\end{array} \\ \text { January } & 25.0 & 29.0 & 83 & 94 & 4.5 & 16.6 & 3.61 \\ \text { February } & 26.4 & 28.6 & 83 & 79 & 5.8 & 18.9 & 4.02 \\ \text { March } & 24.7 & 28.4 & 83 & 80 & 4.1 & 15.9 & 3.41 \\ \text { April } & 26.5 & 29.1 & 83 & 77 & 5.6 & 17.2 & 3.65 \\ \text { May } & 26.8 & 29.4 & 79 & 78 & 6.2 & 16.8 & 3.60 \\ \text { June } & 25.9 & 28.8 & 78 & 66 & 5.6 & 15.2 & 3.21 \\ \text { July } & 26.0 & 28.4 & 75 & 89 & 7.3 & 17.8 & 3.72 \\ \text { August } & 25.8 & 28.3 & 74 & 89 & 7.2 & 18.9 & 3.98 \\ \text { September } & 25.9 & 28.8 & 72 & 89 & 7.8 & 21.2 & 4.45 \\ \text { October } & 27.5 & 30.4 & 71 & 83 & 7.2 & 20.9 & 4.63 \\ \text { November } & 25.2 & 30.6 & 72 & 80 & 7.0 & 20.4 & 4.49 \\ \text { December } & 25.7 & 29.6 & 81 & 78 & 3.9 & 15.5 & 3.49 \\ \text { Average } & 25.9 & 29.1 & 78 & 82 & 6.0 & 17.9 & 3.86\end{array}$

Gambar 3 Data ETo (sumber : BMKG Serang)

\subsection{Data Koefisien Tanaman $(\mathrm{Kc})$}

Berikut data koefisien tanaman menurut $F A O$ varietas biasa dalam buku kriteria perencanaan irigasi kp.01 tahun 2013 : 
Tabel 4 Data Koefisien Tanaman (Kc)

\begin{tabular}{ccccc}
\hline \multirow{2}{*}{ Bulan } & \multicolumn{2}{c}{ Nedeco/Prosida } & \multicolumn{2}{c}{ FAO } \\
\cline { 2 - 5 } & Varietas Biasa & $\begin{array}{c}\text { Varietas } \\
\text { Unggul }\end{array}$ & Varietas Biasa & $\begin{array}{c}\text { Varietas } \\
\text { Unggul }\end{array}$ \\
\hline 0,5 & 1,20 & 1,20 & 1,10 & 1,10 \\
1,0 & 1,20 & 1,27 & 1,10 & 1,10 \\
1,5 & 1,32 & 1,33 & 1,10 & 1,05 \\
2,0 & 1,40 & 1,30 & 1,10 & 1,05 \\
2,5 & 1,35 & 1,30 & 1,10 & 0,95 \\
3,0 & 1,24 & 0 & 1,03 & 0 \\
3,5 & 1,12 & - & 0,95 & - \\
4,0 & 0 & - & 0 & - \\
\hline
\end{tabular}

\subsection{Data penggunaan konsumtif tanaman (ETc)}

Penggunaan konsumtif tanaman dapat dirumuskan dengan menggunakan rumus berikut (kriteria perencanaan irigasi kp.01, 2013):

$$
E T c=K c x E T o
$$

Maka didapatkan hasil ETc tiap fase pertumbuhan sebagai berikut :

Tabel 5 Hasil Perhitungan ETc

\begin{tabular}{|c|c|c|c|}
\hline No & & Fase & Nilai ETc (mm/hari) \\
\hline 1 & & Pengolahan lahan & 3,84 \\
\hline 2 & \multirow{3}{*}{ Vegetatif } & Tanam & 0 \\
\hline 3 & & Anakan & 3,97 \\
\hline 4 & & Anakan Maksimum & 4,14 \\
\hline 5 & \multirow{2}{*}{ Generatif } & Berbunga & 3,39 \\
\hline 6 & & Pematangan & 0 \\
\hline
\end{tabular}

\subsection{Data perhitungan kebutuhan air untuk penyiapan lahan}

Untuk perhitungan kebutuhan air untuk penyiapan lahan, menurut Van de Goor dan Zijstra dalam buku kriteria perencanaan irigasi kp.01. rumus yang digunakan sebagai berikut :

$$
I R=\frac{m e^{k}}{e^{k}-1}
$$

Didapat hasil perhitungan kebutuhan air untuk penyiapan lahan sebesar $6,8 \mathrm{~mm} / \mathrm{hari}$

\subsection{Data evaporasi (Eo)}

Data evaporsai didapat dengan rumus 1,1 x ETo selama masa pertumbuhan sesuai dengan fase pertumbuhan padi. Berikut hasil perhitungannya :

\begin{tabular}{|c|c|c|c|c|}
\hline No & & Fase & Jumlah Hari & $\begin{array}{c}\text { Nilai } \\
\text { Evaporasi } \\
\text { (mm/hari) }\end{array}$ \\
\hline 1 & & solahan lahan & 30 & 3,84 \\
\hline 2 & \multirow{3}{*}{ Vegetatif } & Tanam & 0 & 3,97 \\
\hline 3 & & Anakan & 20 & 3,97 \\
\hline 4 & & $\begin{array}{l}\text { Anakan } \\
\text { Maksimum }\end{array}$ & 34 & 4,42 \\
\hline 5 & \multirow{2}{*}{ Generatif } & Berbunga & 35 & 4,01 \\
\hline 6 & & Pematangan & 31 & 3,96 \\
\hline & \multicolumn{2}{|c|}{ Jumlah } & 150 & \\
\hline
\end{tabular}

Tabel 6 Hasil Perhitungan Evaporasi 


\subsection{Data hujan}

Data hujan diambil dari BMKG Serang dan diolah menggunakan aplikasi Cropwat versi 8 beta dan dihitung manual agar mendapat nilai curah hujan efektif. Berikut hasilnya berupa grafik :

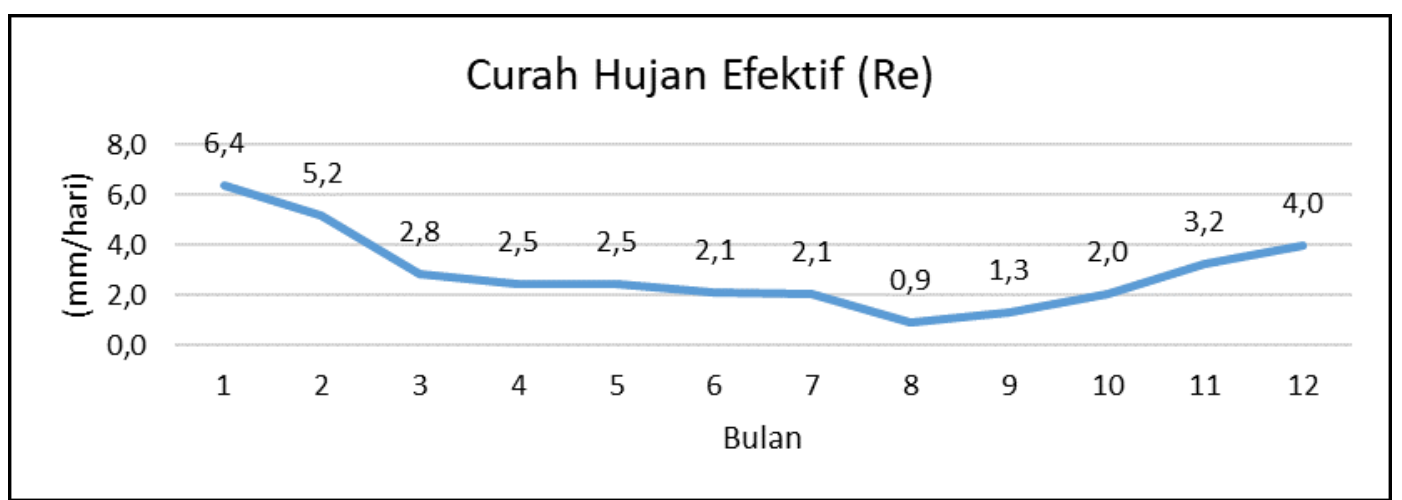

Gambar 4 Hasil Perhitungan Curah Hujan Efektif

\subsection{Analisa kebutuhan air tiap fase pertumbuhan}

Untuk menentukan kebutuhan air tiap fase pertumbuhan menggunakan rumus berikut (kriteria perencanaan irigasi kp.01, 2013):

$N F R=E T c+P+W L R-R e$

Berikut tabel yang berisikan data-data yang dibutuhkan untuk perhitungan kebutuhan air irigasi tiap fase pertumbuhan dan hasil perhitungan NFR :

Tabel 7 Hasil Perhitungan NFR Tiap Fase Pertumbuhan

\begin{tabular}{|c|c|c|c|c|c|c|c|c|}
\hline No & & ase & $\begin{array}{c}\text { Jumlah } \\
\text { Hari }\end{array}$ & $\begin{array}{l}\text { Nilai ETc } \\
\text { (mm/hari) }\end{array}$ & $\begin{array}{c}\text { Nilai P } \\
(\mathrm{mm} / \mathrm{hari})\end{array}$ & $\begin{array}{c}\text { Nilai WLR } \\
\text { (mm/hari) }\end{array}$ & $\begin{array}{c}\mathrm{Re} \\
\text { (mm/hari) }\end{array}$ & $\begin{array}{c}\text { NFR } \\
\text { (mm/hari) }\end{array}$ \\
\hline 1 & \multirow[b]{2}{*}{ Vegetatif } & Anakan & 20 & 3,97 & 2 & 3,33 & 5,2 & \multirow{2}{*}{$\begin{array}{l}4,1 \\
6,67\end{array}$} \\
\hline 2 & & $\begin{array}{l}\text { Anakan } \\
\text { Maksimum }\end{array}$ & 34 & 4,14 & 2 & 3,33 & 2,8 & \\
\hline 3 & \multirow{2}{*}{ Generatif } & Berbunga & 35 & 3,39 & 2 & 3,33 & 2,5 & 6,22 \\
\hline 4 & & Pematangan & 31 & 0 & 2 & 3,33 & 2,5 & 2,83 \\
\hline
\end{tabular}

Hasil perhitungan NFR diatas lalu dikonversi dari mm.hari ke liter/detik dalam 1 ha. Berikut hasil konversi NFR :

Tabel 8 Hasil Konversi Data NFR

\begin{tabular}{|c|c|c|c|c|c|}
\hline No & & Fase & $\begin{array}{c}\text { Jumlah } \\
\text { Hari }\end{array}$ & $\begin{array}{c}\text { NFR } \\
\text { (mm/hari) }\end{array}$ & $\begin{array}{c}\text { NFR } \\
\text { (liter/detik) }\end{array}$ \\
\hline 1 & \multicolumn{2}{|c|}{ Pengolahan Lahan } & 30 & 6,8 & 0,79 \\
\hline 2 & \multirow[b]{2}{*}{ Vegetatif } & Anakan & 20 & 4,1 & 0,47 \\
\hline 3 & & $\begin{array}{l}\text { Anakan } \\
\text { Maksimum }\end{array}$ & 34 & 6,67 & 0,77 \\
\hline 4 & \multirow{3}{*}{ Generatif } & Berbunga & 35 & 6,22 & 0,72 \\
\hline 5 & & Pematangan & 31 & 2,83 & 0,33 \\
\hline & & Rata-rata & & 5,32 & 0,61 \\
\hline
\end{tabular}

Dari tabel diatas maka dapat dibat grafik sebagai berikut : 


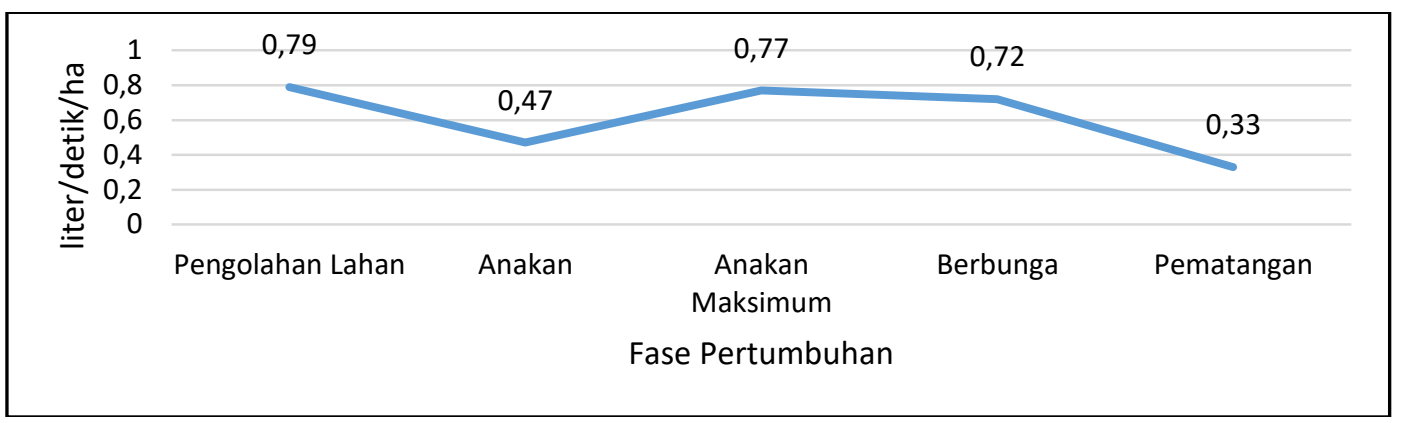

Didapat nilai kebutuhan irigasi sawah padi tertinggi pada fase pengolahan lahan sebesar 0,79 liter/detik dan nilai kebutuhan air irigasi sawah padi terendah terjadi pada fase pematangan sebesar 0,33 liter/detik. Menurut buku kriteria perencanaan irigasi bahwa pada masa pengolahan lahan banyak menggunakan air untuk penjenuhan tanah agar bisa digarap sedangkan pada fase pematangan hanya membutuhkan sedikit air saja karena jika terendam padi akan jatuh dan membusuk jika terendam air. Berikut hasil perhitungan kebtuhan air irigasi sawah padi tiap saluran dan luas garapannya :

Tabel 9 Kebutuhan Air Irigasi Tiap Saluran

\begin{tabular}{|c|c|c|c|c|c|c|c|c|c|c|}
\hline \multirow[b]{2}{*}{ No } & \multirow[b]{2}{*}{ Nama Saluran } & \multirow{2}{*}{\multicolumn{2}{|c|}{$\begin{array}{l}\text { Areal Lahan } \\
\quad(\mathrm{Ha})\end{array}$}} & \multirow{2}{*}{\multicolumn{2}{|c|}{$\begin{array}{c}\text { Luas } \\
\text { Areal } \\
\text { Garapan } \\
(\mathrm{Ha})\end{array}$}} & \multicolumn{5}{|c|}{ Nilai Kebutuhan Air (liter/detik) } \\
\hline & & & & & & $\begin{array}{c}\text { Pengolahan } \\
\text { Lahan } \\
(0,79) \\
\end{array}$ & $\begin{array}{c}\text { Anakan } \\
(0,47)\end{array}$ & $\begin{array}{c}\text { Anakan } \\
\text { Maks } \\
(0,77)\end{array}$ & $\begin{array}{c}\text { Berbunga } \\
(0,72)\end{array}$ & $\begin{array}{c}\text { Pemata } \\
\text { nagan } \\
(0,33) \\
\end{array}$ \\
\hline 1 & $\begin{array}{l}\text { Saluran } \\
\text { Sekunder } \\
\text { Kesampangan }\end{array}$ & 588,2 & & & & & & & & \\
\hline $\mathrm{a}$ & KS.3.ki & 103,7 & & 56 & & 44,24 & 26,32 & 43,12 & 40,32 & 18,48 \\
\hline $\mathrm{b}$ & KS.3.ka & 67,5 & & 32 & & 25,28 & 15,04 & 24,64 & 23,04 & 10,56 \\
\hline c & KS.2 & 125 & & 60 & & 47,4 & 28,2 & 46,2 & 43,2 & 19,8 \\
\hline d & KS.1.ki & 121,2 & & 60 & & 47,4 & 28,2 & 46,2 & 43,2 & 19,8 \\
\hline $\mathrm{e}$ & KS.ka.1 & 126,4 & & 60 & & 47,4 & 28,2 & 46,2 & 43,2 & 19,8 \\
\hline $\mathrm{f}$ & KS.ka.2 & 44,4 & & 20 & & 15,8 & 9,4 & 15,4 & 14,4 & 6,6 \\
\hline \multicolumn{4}{|c|}{ Jumlah } & & & 227,52 & 135,36 & 221,76 & 207,36 & 95,04 \\
\hline \multirow[b]{2}{*}{ No } & & & & das & \multicolumn{6}{|c|}{ Nilai Kebutuhan Air (liter/detik) } \\
\hline & $\begin{array}{l}\text { Nama } \\
\text { Saluran }\end{array}$ & $\begin{array}{c}\text { Areal } \\
\text { Lahan (Ha) }\end{array}$ & $\begin{array}{r}\mathrm{A} \\
\mathrm{Ga} \\
(\mathrm{l}\end{array}$ & $\begin{array}{l}\text { eal } \\
\text { apan } \\
\text { Ia) }\end{array}$ & Pen & $\begin{array}{l}\text { golahan } \\
\text { ahan } \\
0,79)\end{array}$ & kan & $\begin{array}{l}\text { Anakan } \\
\text { Maks } \\
(0,77)\end{array}$ & $\begin{array}{c}\text { Berbunga } \\
(0,72)\end{array}$ & $\begin{array}{l}\text { ematangan } \\
(0,33)\end{array}$ \\
\hline 2 & $\begin{array}{l}\text { Saluran } \\
\text { Sekunder } \\
\text { Bayongbong }\end{array}$ & 350,1 & & & & & & & & \\
\hline a & BYB.2.ki.1 & 130,3 & & 60 & & 47,4 & 3,2 & 46,2 & 43,2 & 19,8 \\
\hline $\mathrm{b}$ & BYB.2.ki.2 & 104,3 & & 50 & & 47,4 & 3,2 & 46,2 & 43,2 & 19,8 \\
\hline $\mathrm{c}$ & BYB.1.ki & 115,5 & & 50 & & 47,4 & 3,2 & 46,2 & 43,2 & 19,8 \\
\hline \multicolumn{3}{|c|}{ Jumlah } & & & & 42,2 & 4,6 & 138,6 & 129,6 & 59,4 \\
\hline
\end{tabular}

Dikarenakan tidak selalu dialiri dari bendung pamarayan akibat perbaikan saluran maka dibuatkan jadwal buka tutup tiap saluran agar tidak terjadi perebutan air dan dilakukan sistem rotasi/bergiliran. Pada bayongbong berada di hulu maka air dibuka pada tanggal 2 november 2019 selama 24 jam dan pada tanggal 3 november dibuka selama 12 jam setelah saluran sekunder kesampangan. Tanggal 4 november 2019 sampai tanggal 28 desember 2019 dilakukannya buka tutup pintu saluran secara bergantian setiap 2 hari sekali. Pada tanggal 1 januari 2020 sampai 20 maret 2020 air dibuka terus menerus dikarenakan tidak ada pekerjaan perbaikan saluran pada waktu itu. Pada bulan april 2020 proyek perbaikan saluran dilanjutkan dan terjadi penutupan sementara. Sebab di bulan april sudah mulai pengeringan dan air yang dibutuhkan hanya sedikit saja sedangkan pada 
saluran kesampangan berada di hilir maka air dibuka pada tanggal 1 november 2019 selama 24 jam dan pada tanggal 3 november dibuka selama 12 jam. Tanggal 4 november 2019 sampai tanggal 28 desember 2019 dilakukannya buka tutup pintu saluran secara bergantian setiap 2 hari sekali. Pada tanggal 1 januari 2020 sampai 20 maret 2020 air dibuka terus menerus dikarenakan tidak ada pekerjaan perbaikan saluran pada waktu itu. Pada bulan april 2020 proyek perbaikan saluran dilanjutkan dan terjadi penutupan sementara. Sebab di bulan april sudah mulai pengeringan dan air yang dibutuhkan hanya sedikit saja.

Jadwal penanaman yang seharusnya dilakukan, yaitu pada tanggal 7 November 2019 - 5 Desember 2019 dilakukan pengolahan lahan selama 30 hari. Pada tanggal 6 Desember 2019 - 25 Desember 2019 dilakukan penanaman anakan selama 20 hari. Pada tanggal 26 Desember 2019 - 28 Januari 2020 dilakukan pemberian air untuk masa anakan maksimum selama 34 hari. Pada tanggal 29 Januari 2020 - 3 Maret 2020 dilakukan pemberian air untuk masa padi berbunga selama 35 hari. Pada tanggal 4 Maret 2020 - 3 April 2020 dilakukan pemberian air dan pengurangan (jika berlebih) pada masa pematangan dan sekaligus mulai pengeringan agar tidak terlalu basah yang menimbulkan tanaman padi akan jatuh dan membuat kualitas padi rusak.

\section{KESIMPULAN}

Kesimpulan yang didapat dari penelitian ini adalah sebagai berikut :

1. Didapat kebutuhan air untuk pengolahan lahan sebesar $6,8 \mathrm{~mm} / \mathrm{hari}$ atau 0,79 liter/detik/ha. Didapat nilai air kebutuhan air untuk anakan sebesar $4,1 \mathrm{~mm} / \mathrm{hari}$ atau 0,47 liter/detik/ha. Didapat nilai kebutuhan air untuk anakan maksimum sebesar $6,67 \mathrm{~mm} / \mathrm{hari}$ atau 0,77 liter/detik/ha. Didapat nilai kebutuhan air untuk berbunga sebesar 6,22 $\mathrm{mm} / \mathrm{hari}$ atau 0,72 liter/detik/ha. Didapat nilai kebutuhan air untuk pematanagan sebesar $2,83 \mathrm{~mm} / \mathrm{hari}$ atau $0,33 \mathrm{liter} / \mathrm{detik} / \mathrm{ha}$. Kebutuhan air terbesar terjadi pada fase pengolahan lahan yaitu pada saluran sekunder Kesampangan sebesar 227,52 liter/detik dan pada saluran sekunder Bayongbong sebesar 142,2 liter/detik. Kebutuhan air terkecil terjadi pada fase pematangan yaitu pada saluran sekunder Kesampangan sebesar 95,04 liter/detik dan pada saluran sekunder Bayongbong sebesar 59,4 liter/detik.

2. Cara pembagian air yang dilakukan dengan cara rotasi atau bergiliran untuk menggunakan air.

3. Jadwal penanaman yang seharusnya dilakukan, yaitu pada tanggal 7 November $2019-5$ Desember 2019 dilakukan pengolahan lahan selama 30 hari. Pada tanggal 6 Desember 2019 - 25 Desember 2019 dilakukan penanaman anakan selama 20 hari. Pada tanggal 26 Desember 2019 - 28 Januari 2020 dilakukan pemberian air untuk masa anakan maksimum selama 34 hari. Pada tanggal 29 Januari 2020 - 3 Maret 2020 dilakukan pemberian air untuk masa padi berbunga selama 35 hari. Pada tanggal 4 Maret 2020 - 3 April 2020 dilakukan pemberian air dan pengurangan (jika berlebih) pada masa pematangan dan sekaligus mulai pengeringan agar tidak terlalu basah yang menimbulkan tanaman padi akan jatuh dan membuat kualitas padi rusak.

\section{SARAN}

1. Perhitungan kebutuhan air yang peneliti lakukan pada penelitian ini masih menggunakan cara manual (terkecuali untuk menghitung rata-rata hujan dan evapotranspirasi). Disarankan apabila ada peneliti yang melakukan penelitian yang sama untuk menghitung kebutuhan air sebaiknya menggunakan aplikasi Cropwat versi 8 beta.buatan FAO.

2. Penelitian selanjutnya sebaiknya dilakukan pada saluran lain seperti saluran sekunder bitung, kepuh dan ondar andir yang ada di kecamatan Ciruas, karena dalam penelitian ini hanya ada 2 saluran sekunder, yaitu saluran sekunder kesampangan dan bayongbong.

3. Jika ada peneliti yang tertarik untuk melakukan penelitian yang sama di kecamatan Ciruas disarankan untuk tidak melakukan penelitian pada masa tanam ke-3 (MT.III), dikarenakan pada masa tersebut biasanya terjadi kemarau panjang sehingga petani melakukan pengistirahatan tanah dan tidak ada penanaman padi.

\section{DAFTAR PUSTAKA}

Akmal, Masimin dan Meilianda (2014). Efesiensi Irigasi pada Petak Tersier Di Daerah Irigasi Lawe. Hal. 18 Vol. 3 No. 3. Universitas Syiah Kuala.

Anonim (2013). Kriteria Perencanaan Irigasi KP.01.Kementerian Pekerjaan Umum.Jakarta. 
Ardana, Sudika, dan Suardika. (2019). Analisis Kebutuhan Air Irigasi di Daerah Irigasi Tengkulak Mawang pada Daerah Aluran Sungai (DAS) Petanu Kabupaten Gianyar.Vol. 11 No.2. Universitas Ngurah Rai.

Handika, Sumiyati dan Wijaya (2015). Analisis Neraca Air Irigasi untuk Tanaman Padi pada Subak Jaya sebagai Subak Natak Tiyis . Universitas Udayana.

Heryani dkk (2017), Analisis Ketersediaan dan Kebutuhan Air Irigasi pada Lahan Sawah di Provinsi Sulawesi Selatan. Vol.41 No.2. Balai Penelitian Agroklimat dan Hidrologi.

Hidayat, Irawan dan Hermawan. (2020). Analisis Kebutuhan Air Irigasi Berbasis Regulasi Jadwal Tanam dan Reduksi Lahan Tanam pada Daerah Irigasi Cimulu.Vol.1 No.2. Universitas Siliwangi.

Huda, Harisuseno dan Priyantoro. (2012). Kajian Sistem Pemberian Air Irigasi Sebagai Penyusunan Jadwal Rotasi pada Daerah Irigasi Tumpang Malang. Vol. 3 No. 2. Universitas Brawijaya.

Imam dan Soebagio. (2019). Optimasi Ketersediaan dan Kebutuhan Air Irigasi di Daerah Aliran Sungai Jajar Daerah Irigasi Hatigoro Demak. Vol.7 No.3 Hal 183. Universitas Wijaya Kusuma Surabaya.

Kunaifi, Limantara dan Priyantoro. (2011). Pola Penyediaan Air D.I Tibunangka dengan Sumur Renteng pada Sistem Suplesi Renggung . Vol. 2 No.1. Universitas Brawijaya.

Lestari, Sayekti dan Prayogo (2019). Studi Evaluasi Debit Tersedia dan Debit Kebutuhan untuk Pemenuhan Kebutuhan Air Irigasi pada Jaringan Irigasi Tekung Kabupaten Lumajang . Universitas Brawijaya.

Rizqi, Yasar dan Jayanti (2019). Analisis Kebutuhan Air Irigasi Menggunakan Cropwat pada Daerah Irigasi Krueng Jreu Kab. Aceh Besar .Vol4 No.4. Universitah Syiah Kuala.

Saputra.(2018). Analisis Ketersediaan dan Kebutuhan Air Irigasi untuk Pertanian di Kecamatan Padang Genting Kabupaten Tanah Datar.Vol. 2 No.2. Universitas Negeri Padang.

Sari.(2019). Analisis Kebutuhan Air Irigasi untuk Lahan Persawahan Dusun Topongo Desa Awo Gading Kecamatan Lamasi . Vol.4 No.1. Universitas Andi Djemma.

Sari, Fadli dan Zulkarnaen (2019), Model Penentuan Kebutuhan Air Pertanian dengan Pendekatan Need Field Water (NFR). Vol.2 No.2. Universitas Prima Indonesia.

Sidharta (1997), Irigasi dan Bangunan Air . Gunadarma.

Thohir, Sayekti dan Ismoyo, (2017). Studi Pola Pemberian Air Irigasi Berdasarkan Faktor Jarak Sebagai Upaya Pemenuhan Kebutuhan Air di D.I Jeruk Taman Probolinggo. Universitas Brawijaya

Wahyudi dan Nugroho (2017). Analisa Kebutuhan Air pada Petak Tersier DI Penungkulan Universitas Muhammadiyah Purworejo. 